\title{
La globalización de la fruta, los cambios locales y el desigual desarrollo rural en América Latina: Un análisis crítico del complejo de exportación de fruta chilena
}

\author{
Warwick E. Murray*
}

\begin{abstract}
Some comentators see Chile as the most 'successful' example of a developing country which has become involved in the global fruit export complex. The neoliberal reforms of the 1970s and 1980s helped precipitate a large 'boom' in such exports. At the present time, Chile is the major fruit exporter in the Southern Hemisphere. Inevitably, contact with global forces has induced rapid local and regional change, mediated through (largely) multinational companies. This has fundamentally altered the nature of social and economic relations of production in the Chilean countryside. The objective of this article is to illustrate how neoliberalism has led to unequal and unsustainable rural development in Chile, and how well-targetted state regulation could alleviate some of the problems currently facing the fruit sector. More generally, the article intends to be critical of the neoliberal 'consensus' which is now almost hegemonic among Latin American states.
\end{abstract}

\section{Resumen}

Algunos ven a Chile como el ejemplo más 'exitoso' de un país en desarrollo que exporta fruta no tradicional. Las reformas neoliberales de las décadas de los 70 y 80 ayudaron a precipitar un gran boom en las exportaciones de fruta. Actualmente, Chile es el mayor exportador de fruta en el Hemisferio Sur. Inevitablemente, el contacto con las fuerzas globales ha inducido a un rápido cambio a escala local y nacional, mediado por empresas frutícolas en gran parte multinacionales, quienes han alterado fundamentalmente la naturaleza de las relaciones sociales y económicas de la producción en el campo chileno. El objetivo específico de este artículo es ilustrar cómo el neoliberalismo ha llevado a un desarrollo rural desigual en el campo chileno y, más crucialmente, cuán útiles pueden ser la efectiva intervención y regulación del Estado para contribuir a aliviar tensiones. Desde un punto de vista más general, este artículo intenta adoptar una posición crítica del 'consenso' neoliberal imperante en América Latina.

* Department of Geography, School of Social and Economic Development, The University of the South Pacific, Fiji Islands, e-mail: murray_w@usp.ac.fj 
Warwick E. Murray

I. INTRODUCCIÓN. LA AGRICULTURA GLOBAL, LA FRUTA Y AMÉRICA LATINA

$\mathrm{L}$ os mecanismos intercontinentales que constituyen el sistema global agrícola se están profundizando y ampliando (Le Heron, 1993). De los varios sectores dentro de la agricultura, el sistema frutícola es quizás el más visiblemente globalizado (Friedland, 1994). Los patrones de comercio e inversión dentro de este sector forman 'cadenas globales de productos' o, más precisamente, 'complejos' que unen todos los rincones del mundo (Whatmore, 1995). El cambio cultural y económico que trae la globalización ha brindado una 'ventana' de oportunidades de exportación para una serie de países 'en desarrollo'. Más y más los países del Hemisferio Sur están penetrando importantes mercados 'contraestacionales' (invierno en el Hemisferio Norte); ellos son Japón, los Estados Unidos y la Unión Europea. Lo anterior ha facilitado en algunos países latinoamericanos (por ejemplo, Chile, Argentina, Guatemala, Honduras y Paraguay) la reestructuración económica neoliberal, la cual incluye la apertura de las economías a la inversión extranjera, la liberalización de los mercados, y las medidas para elevar la competitividad de las exportaciones. En algunos casos se han alcanzado 'éxitos' macroeconómicos considerables, contribuyendo así las exportaciones de fruta no tradicional al balance del comercio, las reservas de cambio extranjero y el Producto Geográfico Bruto (PGB).

Chile es mencionado por algunos como el ejemplo más 'exitoso' de un país en desarrollo exportador de fruta no tradicional. Las reformas neoliberales de las décadas de los años setenta y ochenta ayudaron a precipitar un gran boom en las exportaciones. Actualmente, Chile es el mayor exportador de fruta en el $\mathrm{He}$ - misferio Sur (Murray, 1997a). Inevitablemente, el contacto con las fuerzas globales ha inducido un rápido cambio a escala local y nacional, mediado por empresas frutícolas en gran parte multinacionales, que han alterado fundamentalmente la naturaleza de las relaciones sociales y económicas de la producción en el campo chileno. Algunos comentaristas celebran el auge del neoliberalismo y la orientación hacia el exterior en los sectores rurales chilenos - ellos insisten en que la introducción de los imperativos de la competencia ha aumentado la eficiencia precipitando una gama de repercusiones que son indicativas de 'desarrollo'-, por ejemplo, han aumentado las oportunidades de trabajo, el progreso de la infraestructura como también el bienestar material (Hojman, 1993; Universidad Católica de Chile, 1991). Siendo lo anterior en parte cierto, este artículo plantea que tales reflexiones no expresan por completo la gama de las tensiones sociales, económicas y ambientales que han evolucionado en las localidades pertinentes y en el país completo debido al crecimiento de las exportaciones de fruta no tradicional (XFNT). Estas tensiones siguen exacerbando las desigualdades espaciales y sociales, aumentando la dependencia de fuerzas determinadas más bien desde el exterior, teniendo, a largo plazo, el potencial de debilitar la sustentabilidad de los complejos de exportación de fruta locales y, tal vez, nacionales. Así, el modelo imperante es defectuoso en dos aspectos. Primero, desde una perspectiva de desarrollo ajena a la corriente ortodoxa, ${ }^{1}$ se puede cuestionar la existencia de un 'desarrollo' rural real. Segundo, las amenazas a la capacidad de sustento, que sin duda existen, socavan la habilidad

\footnotetext{
1 No existe ninguna perspectiva de desarrollo de una tendencia claramente "no-ortodoxa'. Esto se debe a que no existe un enfoque único de desarrollo 'ortodoxo'. En este artículo,
} 
del paradigma ortodoxo para cumplir con los objetivos a los que aspira a largo plazo. Este artículo plantea que los problemas existentes en el sector han emergido, en gran parte, como consecuencia de una búsqueda dogmática de las políticas socioeconómicas neoliberales en el Chile rural. El objetivo específico de este artículo es ilustrar cómo el neoliberalismo ha llevado a un desarrollo rural desigual ${ }^{2}$ en el campo chileno y, más crucialmente, cuán útiles pueden ser la efectiva intervención y regulación del Estado para ayudar a aliviar tensiones. Desde un punto de vista más general, este artículo intenta adoptar una posición crítica del 'consenso' neoliberal imperante en América Latina. La globalización de la agricultura (especialmente de la fruta) ofrece potenciales beneficios a los países latinoamericanos que no pueden ser menospreciados. Sin embargo, el optimizar estas oportunida-

desarrollo 'ortodoxo' se define como el llamado 'ajuste estructural' normalmente (pero no siempre) favorecido por las instituciones de préstamo global tales como el Banco Mundial y el Fondo Monetario Internacional, los cuales enfatizan una orientación exportadora, la eficiencia y el crecimiento económico. Si bien es cierto no se rechazan las potenciales ventajas de los imperativos anteriores per se, el desarrollo "no-ortodoxo", por otra parte, enfatiza temas como la equidad, la sustentabilidad, la inclusión política y la armonía social. Se reconoce que tal concepción es muy simplista. No obstante, la exploración de las complejidades de tal debate está más allá del alcance de este artículo.

${ }^{2} \mathrm{El}$ desarrollo rural desigual se define aquí como 'desarrollo' rural que exacerba la desigualdad y que es 'no-sustentable'. Algunos argumentarian que ésta es una característica inherente de un desarrollo rural capitalista de tendencia dominante (Shepherd, 1998). Para otros, tales como los 'neoestructuralistas' (Dietz, 1995; Sunkel, 1993) a pesar de que los elementos de 'desigualdad' son inevitables, éstos se pueden reducir a niveles tolerables y aún 'óptimos' a través de la intervención estatal (incluyendo el apoyo a la sociedad civil) diseñada para engendrar un crecimiento económico rural equitativo y sustentable. des está supeditado a la maximización de la equidad y de la capacidad de sustentabilidad a largo plazo. Tal proceso de optimización requiere mirar más allá del neoliberalismo y necesita un viraje paradigmático que amplíe el concepto de desarrollo general como también rural (Shepherd, 1998).

\section{EL COMPLEJO GLOBAL DE AGRO- ALIMENTOS Y EL DESARROLLO DESIGUAL EN AMÉRICA LATINA}

Antes de esbozar la naturaleza del complejo de la globalización de la fruta fresca, y analizar sus repercusiones en el cambio en el Chile rural, es necesario resumir brevemente algunas ideas en evolución sobre la naturaleza del complejo agrícola global en general. La globalización de la fruta no se puede separar teórica o empíricamente de este último. Es más, es útil ofrecer algunas ideas preliminares sobre los impactos de la globalización de la agricultura en términos de la perpetuación del desarrollo desigual en los países del Tercer Mundo y las localidades que los constituyen.

Ultimamente, la agricultura ha cambiado de manera casi irreconocible. Es evidente que la naturaleza del cultivo agrícola y la producción de alimentos se ha movido desde un modelo tradicional basado en la producción familiar para mercados locales y nacionales, a lo que Whatmore (1995) ha llamado un 'complejo agroalimenticio' con un alcance global. Este complejo se ha definido como "el set de actividades y relaciones que interactúan para determinar qué, cuánto, y por qué método y para quién se producen y distribuyen los alimentos" (p. 37). Whatmore conceptualiza el sistema como compuesto de cuatro partes interrelacionadas: la industria de la agrotecnología (A), la industria de los cultivos agrícolas (B), la industria alimenticia 
Warwick E. Murray

(C) y el consumidor de alimentos (D). Entre estos grupos, existen varios grupos de cuerpos reguladores; entre A y $B$ se conceptualizan varias sucursales de extensión (comercio minorista, consultoría y crédito); estas actividades son realizadas por una combinación de agentes comerciales, estatales y reguladores. Entre B y C, cuerpos principalmente estatales regulan la calidad y comercialización, además de desempeñar otras actividades de intervención. Finalmente, entre C y D entidades, principalmente estatales, desempeñan labores reguladoras tales como la calidad y seguridad de los alimentos y las medidas de nutrición y salud. Las relaciones interactivas y mutuamente determinantes que existen entre las varias partes del complejo de Whatmore no le da ascendencia a ningún sector sobre el otro. Al centro del asunto, la nueva disposición proyecta una nueva luz en los limites conceptuales tradicionales entre sectores primarios, secundarios y terciarios de la economía que han caracterizado el análisis en la geografía económica en general (Gwynne, 1998).

Mientras que en el pasado los asuntos de la producción alimenticia y de la asignación de recursos agrícolas se resolvian a un nivel de espacios productivos locales, hoy día se tratan a una escala global. De acuerdo a Whatmore, este cambio ha sido empujado en gran parte por el aumento de la agroindustria y su búsqueda de ganancias. El campo de juego de estos aspectos, a través de una combinación de integración vertical directa (basada en la propiedad) e indirecta (basada en un contrato), se ha globalizado cada vez más. Por lo tanto, las diferentes partes del complejo agroalimenticio están insertas en distintas ubicaciones internacionales. Al emplear modos de análisis de regulación, un número de autores (Whatmore, 1995; Le Heron, 1993; Friedman y McMichael,
1989) ven este cambio como una transición entre los diferentes 'regímenes de acumulación' en el complejo agrícola llamada 'food regimes' o 'regimenes alimenticios'. Dentro de esta conceptualización, el período previo a la Primera Guerra Mundial se ha indicado como 'el primer régimen alimenticio' asociado a los patrones de comercio e inversión establecidos durante el período colonial y a la persistencia de las relaciones neocoloniales de la producción posterior a la independencia. Siguiendo a la crisis de reestructuración precipitada por la Gran Depresión y la Segunda Guerra Mundial, se inició un segundo régimen alimenticio. Este se caracterizó por la reestructuración del sector agroalimenticio principalmente a través de capital transnacional (Le Heron, 1993). Según Whatmore, uno de los mayores impactos de éstos ha sido la creación de una nueva división internacional del trabajo en la agricultura, la que respalda la globalización reciente. ${ }^{3}$

\section{A. Las exportaciones agricolas no tradicionales en América Latina y las relaciones de poder globales}

Siguiendo la crisis de endeudamiento de principios de los años 80, muchos países latinoamericanos volvieron la vista a la promoción de exportaciones agrícolas

\footnotetext{
3 Una discusión amplia y completa del concepto de los regímenes alimenticios no es posible en el espacio limitado aquí. Vale la pena destacar que de acuerdo a los defensores de esta tesis, en este momento somos testigos de la agonía de una crisis de reestructuración de la agricultura, la que está asentando las bases para una transición hacia un tercer régimen alimenticio. Esta crisis se caracteriza por una gama de problemas que incluyen una crisis en el comercio mundial originando una "inestabilidad en los precios, una avería en los acuerdos multilaterales y una mayor competencia en los mercados exportadores" (Le Heron, 1993). Otra caracte-
} 
no tradicionales ${ }^{4}$ como una solución para sus males económicos. Este proceso formó parte de un mayor viraje hacia un modelo de desarrollo orientado hacia el exterior que siguió a lo que fue percibido como fracaso del modelo de la industrialización para la sustitución de importaciones (Barham et al., 1992). Para tales países, la globalización de la agricultura ofreció una 'ventana' de oportunidades para las exportaciones permitiéndoles explotar sus ventajas comparativas en la producción de ítemes contraestacionales en el mercado global. A pesar

rística de esta crisis es la incapacidad del GATT para resolver los problemas más abrumantes en el comercio agrícola. Los comentaristas sólo pueden especular sobre la posible naturaleza del próximo tercer régimen. Para Le Heron, nos estamos moviendo desde una etapa intensiva (el segundo régimen alimenticio) a una etapa integrada que se caracteriza por "un enfoque emergente en 'alimentos formulados y frescos', ofreciendo los servicios especialmente a diferentes consumidores de altos ingresos y distintos orígenes raciales" (p. 22, 1993). Estos servicios pueden implicar una mayor importancia para la producción biotecnológica de alimentos, lo que a través de la diversidad productiva de las economías avanzadas puede reducir la necesidad de 'ir al extranjero' disminuyendo la inversión en los países periféricos. El concepto de los regimenes alimenticios y los regimenes de acumulación general ha sido criticado por algunos como demasiado generalizador y excesivamente determinista. En su discusión de estas ideas relacionadas con la agricultura en América Latina, Llambí (1991) acusa a los autores de, por ejemplo, 'envasar el vino viejo en botellas nuevas'. Por otra parte, el enfoque del régimen ofrece un marco de organización útil para el análisis de la globalización de la agricultura.

${ }^{4}$ Barham et al. (1992) definen las XANT como aquellas exportaciones que caben dentro de al menos una de las tres categorías siguientes: 1) Un producto de exportación que no ha sido producido antes en un país dado (Ej. arvejas en Guatemala); 2) Un producto que era tradicionalmente producido para el consumo doméstico que ahora es comercializado internacionalmente $(\mathrm{Ej}$. flores en Costa Rica, manzanas en Chile); 3) Un producto de exportación 'tradicional' enviado a un nuevo mercado (Ej. plátanos del Caribe a Rusia). de que el viraje hacia tales productos contribuyó a menguar los efectos de la recesión de los 80, al mismo tiempo éste ha dado origen a una gama de preocupantes problemas a todos los niveles de análisis. Los siguientes son algunos de los impactos generales:

En el modelo contemporáneo del agrocomplejo de Whatmore, la autora no asigna un poder determinante o dominante a ninguno de los elementos en especial dentro del complejo agroalimenticio (aunque la misma implica en su análisis las repercusiones del nuevo sistema para los países en desarrollo). Sin embargo, en el contexto de los países en desarrollo, la asimetría de poder entre los diferentes elementos del complejo es cada vez más clara y significativa en la profundización del desarrollo desigual. ¿Cuáles son las principales repercusiones de la globalización de la agricultura para los países latinoamericanos que están 'enredados' en el nuevo complejo? ¿Cómo puede la participación crear una situación en que las estructuras globales dominen, llevando a una profundización del desarrollo desigual y no sostenible?

- La globalización de la agricultura se ha caracterizado por la ubicación de la parte 'extractiva' del complejo en los países de América Latina. La mayoría de las empresas que dominan la tecnología química e industrial, la biotecnologia, el marketing, la distribución, el proceso y la venta de productos se encuentran en las economías 'avanzadas'. Tales corporaciones captan gran parte del valor agregado que se genera dentro del complejo (Gwynne, 1998).

- La sustitución de la producción de alimentos por la producción para la exportación ha llevado a una inseguridad alimenticia en los países latinoamericanos, lo que ha conducido a un aumento 
de los alimentos importados en la mayoría de los países (Kay, 1995).

- Aunque la disminución de los impactos más dañinos de la exposición a fuerzas globales es, en teoría, posible a través de la acción estatal, la adopción de las políticas neoliberales en las economías latinoamericanas (la que ha sido necesaria para competir en los mercados globales) significa que la regulación es a menudo mínima, conduciendo a un despliegue de problemas sociales, económicos y ambientales.

- Los países latinoamericanos se han involucrado en un sistema de comercio global a menudo injusto para éstos (como también ineficiente) que se caracteriza por altos niveles de proteccionismo en las economías 'avanzadas'.

- El crecimiento de XANT de América Latina ha conducido a una reasignación de recursos a un sector cuyos productos han sufrido una depreciación en precios a largo plazo relativo a los productos manufacturados debido a una baja elasticidad de demanda (la fruta es una excepción en el sector agrícola, pero esto podría cambiar en el futuro si pierde su estatus de 'exótica' en los mercados). Las consecuencias del comercio de estos productos a largo plazo son preocupantes, dado que la mayoría de los países latinoamericanos son importadores netos de productos manufacturados.

De particular relevancia en este artículo son los impactos locales de la inserción en los mercados globales. En discusiones sobre la globalización de la agricultura se argumenta que las estructuras globales económicas y políticas no pueden determinar del todo los resultados locales y que los actores locales, a través de su respuesta a imperativos estructurales a altas escalas de resolución, pueden provocar una reconstitución del sistema desde el fondo (Le Heron, 1993). Mientras que la propuesta de 'estructuración, ${ }^{5}$ entre actores individuales y las estructuras (Giddens, 1984) debe ser aceptada en teoria y ha sido, sin duda, observada en momentos y lugares específicos (especialmente en el centro económico global), en el contexto de los sectores agroexportadores de América Latina se argumenta que las estructuras globales de influencia determinante a menudo dominan la capacidad de los actores locales de responder efectivamente. Este aspecto forma el principal punto de atención en la discusión del caso chileno. Sin embargo, es importante destacar:

- Al motivar la inserción de los sectores agrícolas en los mercados globales, los gobiernos latinoamericanos han puesto sus localidades a la disposición de fuerzas globales impredecibles y volátiles, las cuales están en gran parte más allá de su control. A menudo en las localidades de XANT se desarrollan monocultivos que son alentados por las compañías exportadoras, lo cual crea una vulnerabilidad económica y ambiental.

$5 \mathrm{El}$ intento de Giddens de resolver el problema de estructura y agencia (o actores) debería "proveer pistas de como no enfocar la Geografia Humana" (Cloke, Philo y Sadler, 1991). Eso quiere decir que la investigación no debería conceptualizar ni la estructura (como en el marxismo estructural) ni los actores (como en el humanismo y algunas formas de postmodernismo) como totalmente determinantes o deterministas. Así, en la teoría de la estructuración, las localidades son los contextos dentro de los cuales los individuos son actores entendidos e informados. Esta información se refiere a la capacidad de inferir de los "procesos de la sociedad y elegir las estrategias y tácticas más ventajosas" (Johnston, 1991). De esta manera, dependiendo de su capacidad de actuar, su localidad puede ser habilitante o limitante. En última instancia, "la Historia no es ni determinada, ni abierta” (Johnston, 1991). 
- Las empresas multinacionales no reguladas (dado el modelo neoliberal) ejercen un gran poder en los mercados locales (Korovkin, 1992). Estos mercados a menudo están compuestos por agricultores políticamente no organizados (el neoliberalismo no promueve la organización civil). Así el cambio global económico y estructural, que sin duda afecta las políticas de las compañias multinacionales, provoca un impacto que condiciona a los individuos en el ámbito local. Lo anterior es de mayor relevancia para los pequeños agricultores.

En sus discusiones sobre las cadenas globales de productos, Gereffi (1994) ve el sistema agrícola global como primeramente impulsado por el comprador, argumentando que los comerciantes mayoristas y las empresas comerciales juegan un papel fundamental y poderoso en el establecimiento de redes de producción descentralizada (Gwynne, 1998). En este sentido, la perspectiva de Gereffi es más relevante para la realidad latinoamericana y es la que será empleada para analizar los impactos de la XFNT chilena al sector frutícola global.

\section{LA GLOBALIZACIÓN DEL COMPLEJO DE FRUTA FRESCA}

Mientras que en general se reconoce la naturaleza dudosa de las conceptualizaciones 'cronológicas', es útil separar el desarrollo del sistema de fruta global en dos períodos diferentes: pre y post Segunda Guerra Mundial. Estas divisiones se unen convenientemente (y no por coincidencia) a aquellas concebidas para los 'regímenes alimenticios' discutidos anteriormente. ${ }^{6}$ La discusión se centra en el segundo de estos períodos.

6 El concepto de los regímenes de fruta todavía tiene que ser explorado en la literatura.

\section{A. El sistema de fruta fresca pre-Segunda Guerra Mundial}

En general, hasta fines de la Segunda Guerra Mundial, el sistema de fruta fresca operaba dentro de una escala de resolución local y nacional. Esta situación estaba en parte determinada tecnológicamente; la infraestructura y las técnicas de transporte internacional de productos perecibles a larga escala no estaban bien desarrolladas. También había un rango de factores económicos y sociales que dificultaban el desarrollo de un sistema globalizado (ver sección postSegunda Guerra Mundial). Una notable excepción al patrón general de suministro de fruta 'localizada' fue la economía del plátano. Los plátanos son fruta relativamente no perecible y pueden resistir un período largo siendo transportados en condiciones 'naturales'. Este comercio de exportación se inició en el siglo XIX, con la exportación de la entonces 'exótica' banana desde las colonias (Asia del Sudeste, América Central y el Caribe) a los poderes coloniales y neo-coloniales (principalmente en Europa). Posteriormente, un número de empresas multinacionales privadas - notablemente Dole, Chiquita y Del Monte- comenzaron a participar en la comercialización de plátanos y la exportación a EE.UU. aumentó preponderantemente (Friedland, 1994).

El sistema de provisión de productos frescos relativamente perecibles a "larga distancia' fue fundado en EE.UU., donde el desarrollo del ferrocarril y luego la tecnología de la refrigeración facilitaron el comercio interregional. La provisión de vegetales inter-Estado, tales como la le-

El hacerlo va más allá del alcance de este artículo. No obstante, se espera que el transmitir la posibilidad de un mejor trabajo en este campo sea una motivación para la incursión investigadora. 
chuga y tomates, representa los primeros ejemplos de la provisión 'fresca' a larga distancia. Este proceso se aplicó a la fruta de Estados Unidos en la década de los años treinta (Friedland et al., 1981).

\section{B. El complejo de fruta fresca de la post-Segunda Guerra Mundial. Las redes globalizantes}

El sistema de la fruta de la post-guerra se ha caracterizado por el aumento de los complejos agroindustriales y agroalimenticios dentro del contexto de la 'industrialización de la agricultura' (Whatmore, 1995). Las empresas multinacionales cada vez más móviles han sido fundamentales en el desarrollo de este sistema - en busca de mano de obra barata, de una infraestructura de transporte relativamente desarrollada al igual que de climas donde sean posibles las cosechas 'contraestacionales' (especialmente para la Navidad). En los años setenta y ochenta, el proceso de globalización se facilitó y aceleró con la adopción de la política económica neoliberal (en parte como un gran medio de ajuste estructural 'recomendado') en una gama de países en desarrollo. La adopción de tales principios, entre otras cosas, ha abierto las economías a la inversión extranjera directa, ha ayudado a mantener bajos los costos de mano de obra como también ha girado el énfasis de las políticas centrales hacia una orientación exportadora. Estas condiciones se han comprobado como ideales para las grandes empresas multinacionales.

Junto a lo anterior, existe una gama de cambios sociales, económicos y tecnológicos relacionados con el sistema frutícola, los que han engendrado su globalización especialmente 'profunda'. Se destacan dos tendencias sociales: En primer lugar, el crecimiento de la clase media en los países capitalistas avanzados después de la Segunda Guerra Mundial condujo a un desarrollo material variado e importante como, por ejemplo, salarios notablemente altos. Los cambios en los estilos de vida de la clase media, especialmente los viajes, contribuyeron al contacto con nuevos alimentos. Aún más, este sector de la sociedad comenzó a tomar conciencia de una dieta saludable. En segundo lugar, el envejecimiento de la población ha tendido a aumentar la demanda por la fruta, ya que las personas mayores tienen el tiempo, especialmente después de jubilar, de informarse de asuntos que les conciernen (la salud y la longevidad); a menudo éstas tienen acceso a recursos y viajan gastando una proporción relativamente alta de sus ingresos en alimentos. Además, los cambios económicos en la postguerra también han sido de importancia, dado que la demanda por la fruta es elástica con respecto al ingreso. Así, el aumento de los salarios en la postguerra ejerció una influencia en el creciente gasto proporcional en fruta. El cambio tecnológico también ha sido instrumental. Primeramente, el desarrollo de las cadenas de refrigeración integradas, o 'cadenas frías' en gran parte adaptadas del sector de vegetales frescos de Estados Unidos, y aplicadas a la fruta en la década de los sesenta, ha permitido el largo trayecto del transporte de los productos frescos perecibles (Carter y Turner, 1988). Segundo, el proceso de la transferencia de la tecnología ha jugado un rol fundamental en el desarrollo del sistema. En los países de ingresos altos este aspecto siempre ha sido regulado por el Estado o por una combinación de empresas privadas y estatales. Los países financieramente constreñidos se han apoyado en empresas multinacionales para la investigación y el desarrollo tecnológico junto con la transferencia de la tecnología - un proceso que ha sido realzado y fortalecido 
por la movilidad de capital (Friedland, 1994).

\section{La geografia del comercio global de fruta}

La combinación de los factores anteriores ha creado una masa de mercado en el mundo capitalista avanzado para una creciente variedad de productos frutícolas, la cuál consta con un sistema global de provisionamiento capaz de ser relativamente confiable a lo largo de todo el año. Esto ha dado origen a un patrón de interacción geográfico complejo y cada vez más voluminoso entre 'Norte y Sur' a través de la inversión y el comercio, existiendo una división internacional de funciones relativamente claras dentro del sistema frutícola global. Así la mayoría de la fruta comercializada es consumida en Norteamérica, Europa Occidental y Japón. Este patrón ha sido respaldado por un aumento significativo en la demanda de la fruta fresca en estas sociedades recientemente. Por ejemplo, en Estados Unidos, entre 1970 y 1989, el consumo de fruta aumentó de 79.4 a 96.6 libras per cápita. En el Reino Unido, se observa una tendencia similar (Cook, 1990). Un aumento relativamente grande de fruta importada en el Medio Oriente, Asia del Este (excluyendo Japón) y América Latina todavía espera por la compensación del dominio de esos mercados; todo esto a pesar de que mientras los ingresos promedios aumenten en Asia del Este y América Latina las futuras importaciones de productos sin duda aumentarán (Murray, 1998a).

La gama de los países exportadores de fruta es bastante más amplia que la de los países importadores de la misma. Los países capitalistas avanzados tales como Estados Unidos, Holanda, Italia, España, Sudáfrica y Nueva Zelandia juegan un rol importante en el suministro de fruta. Sin embargo, como se ha men- cionado antes, el sistema global se ha caracterizado por crecientes exportaciones desde países de ingresos más bajos, especialmente en el Hemisferio Sur. Un número de países tales como Chile, México y Argentina ya juega un papel proporcionalmente muy importante. La variedad de los países exportadores de este tipo se amplía constantemente, especialmente en América Latina, y a una menor escala, Africa y el Pacífico Sur. También en el Hemisferio Norte los países en desarrollo - especialmente de Asia-juegan un rol crecientemente importante (Israel, Turquía, China, India). Sin embargo, el crecimiento de la exportación en estos países no ha sido tan rápido como en el Hemisferio Sur. Esto se debe a que los productores del Norte tienen que competir directamente en los mercados estacionales con productores locales en los mercados mayores quienes, a menudo, están bien protegidos por un muro de barreras tarifarias y no tarifarias. En general, en los países en desarrollo, dado el viraje a las políticas orientadas hacia la exportación, es posible que el aumento en el abastecimiento de productos sobrepase la demanda en el futuro inmediato, lo que implica un aumento en los niveles de competencia y posible baja de precio.

\section{EL BOOM DE LA FRUTA CHILENA}

De alguna manera, la 'ventana' de la globalización se abrió con una fecha altamente fortuita para Chile. Cuando la Junta Militar se tomó el poder en septiembre de 1973 la economía chilena estaba en profundos problemas (Bosworth et al., 1994). En un intento de 'estabilizar' la economía, el régimen militar se embarcó en un austero, rápido y drástico proceso de reforma basado en principios económicos neoliberales (Bosworth et al., 1994). Las tarifas en los insumos importados bajaron, y se redujeron los 
costos de mano de obra a través del desmantelamiento de la actividad organizada; por otra parte, se alentó la inversión extranjera, los procedimientos de exportación se simplificaron y tuvo lugar una serie de grandes devaluaciones.

Las reformas radicales de comercio y mercado permitieron que las ventajas competitivas que Chile posee en la producción de fruta funcionen en el espacio global (Bosworth et al., 1994). Estas incluyen características climáticas, calidad del suelo en las áreas pertinentes, y 'contraestacionalidad' en los mercados globales (Murray, 1997b). Además, a través de estas reformas, se permitió que operaran varias ventajas comparativas inducidas institucionalmente. Al respecto, se destacan tres factores: primero, la inversión en el sector frutícola encabezada por el Estado y centrada en el plan de desarrollo frutícola de Frei en 1968 había determinado los avances tecnológicos dentro del sector (Jarvis, 1992). Segundo, los diversos programas de reforma agraria que comenzaron con la presidencia de Frei (1964-70) y que continuaron con la de Allende (1970-73) y con el primer período de Pinochet (197377 ), terminaron con un altamente ineficiente sistema de propiedad de la tierra precipitando el desarrollo de un mercado de tierra competitivo y eficiente (Gwynne y Meneses et al., 1994; Kay, 1974). Finalmente, los costos de mano de obra bajaron significativamente por las reformas laborales post-golpe. Debido a una tendencia de demanda favorable en los países de altos ingresos, el sector exportador de fruta chilena se expandió rápidamente (Murray, 1998a).

\section{A. Las exportaciones de frutas no tradicionales. La historia de un éxito macroeconómico}

En los veintidós años entre 1974 y 1997 , el valor nominal de las exportaciones de fruta chilena aumentó de US\$ 30 millones a casi US\$ 1400 millones. La figura 1 muestra que entre 1973 y 1982 , dentro del contexto de una política neoliberal extrema, ${ }^{7}$ se registraron aumentos relativamente graduales en el valor nominal de las exportaciones. Entre 1982 y 1983, las consecuencias de la sobrevaloración del peso junto con una empeorada situación económica global disminuyeron los valores nominales de las exportaciones (Gwynne, 1990; Universidad Católica de Chile, 1993). Entre 1983 y 1988, en un intento de levantar la economía chilena de una profunda recesión, el régimen militar adaptó su política neoliberal 'extrema' hacia un modelo de desarrollo más pragmático (Gwynne y Kay, 1997). Dentro de este viraje de políticas de cambio, una serie de devaluaciones del peso junto a diversos incentivos tributarios fueron de gran relevancia para el sector de exportación frutícola (Barham et al., 1992). Con estas políticas, las exportaciones de fruta prosperaban vigorosamente hasta que el crecimiento fue interrumpido por las pérdidas en el mercado de Estados Uni-

\footnotetext{
7 Gwynne y Kay (1997) conceptualizan el neoliberalismo durante la dictadura chilena en términos de dos períodos. El primero (197382) se define como un neoliberalismo 'extremo' durante el cual no hubo políticas agrarias explícitas (excepto por la contrarreforma agraria) dentro del cual se dejó al sector agrícola "a la misericordia de la política macroeconómica neoliberal". El segundo período (1983-89) incluyó un set de políticas más 'pragmáticas', incluyendo un apoyo técnico limitado para los pequeños agricultores, y un limitado proteccionismo de ciertos sectores tradicionales (Ej: remolacha) y un apoyo a precios mínimos de algunos productos clave.
} 
dos, con el episodio de las 'uvas envenenadas' en 1989 (Chilean-American Chamber of Commerce, 1990). A continuación siguieron los dos años de crecimiento más rápido, elevando el valor nominal de las exportaciones de fruta chilena a US\$997.4 millones en 1991. Luego estos valores declinaron por dos años consecutivos. Lo anterior se debió a la imposición de cuotas físicas en el principal mercado importador de manzanas chilenas, la Unión Europea. En los últimos dos años se ha visto un alza impresionante en los valores de las exportaciones debido, en parte, al crecimiento en los mercados de fruta 'no tradicionales' tales como América Latina quien ha recibido ganancias de US\$ 1.000 millones por primera vez. Dentro de este mercado en evolución, las manzanas y en especial la uva han sido de una gran importancia proporcional. Aunque la concentración ha declinado, en 1994 éstas especies fueron responsables de sobre un $70 \%$ de las ganancias (uva $50 \%$, manzanas 20\%).
Las exportaciones de fruta representan el componente primordial en el total de las exportaciones agrícolas. Más aún, el importante papel de las exportaciones agrícolas en el total de las exportaciones ( $11 \%$ en 1994) implica que en 1994 casi un 9\% de las ganancias por exportación se debieron a la fruta. En general, el sector de exportación frutícola jugó un rol crucial en la economía chilena en la década de los años setenta y ochenta contribuyendo a la construcción de una sólida base para los altos niveles de crecimiento que fueron relativamente constantes en ambas décadas (excluyendo 1982 y 1983). Guizás aún más importante es el hecho de que los beneficios y ganancias del sector de exportación frutícola sirvieron para diversificar la economía, aparte de las exportaciones de cobre. En 1971, la minería fue responsable por un $85 \%$ de las ganancias totales de exportación; en 1994 —debido al crecimiento de las exportaciones industriales y agrícolas no tradicionales- la

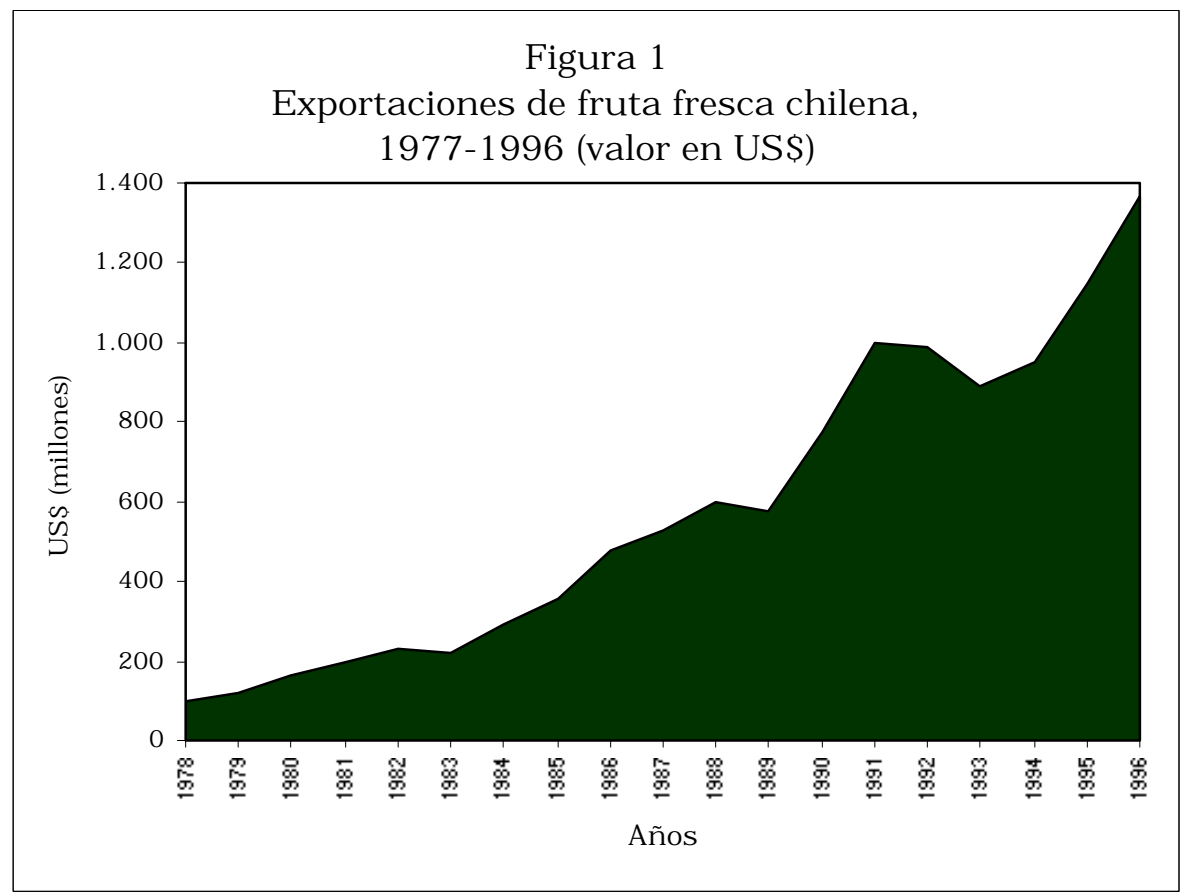

Fuente: Asociación de Exportadores de Chile (varios años). 
Warwick E. Murray

cifra disminuyó a un 44\%. En el escenario mundial, Chile ha llegado a ser el líder en la exportación de fruta en el Hemisferio Sur. Es el mayor exportador de uva de mesa en el mundo y uno de los mayores exportadores de manzanas. En suma, a una escala de análisis macroeconómico, el desarrollo del sector de exportación frutícola chileno representa el 'éxito' más rotundo de la reestructuración neoliberal (Apey, 1995).

\section{LA FRUTA CHILENA EN UNA CADENA DE PRODUCTOS GLOBAL Y EL ROL DE LAS EMPRESAS MULTINACIONALES}

Es útil emplear la adaptación de Gwynne del concepto de Gereffi (1994) de las cadenas de productos globales para así aclarar la estructura y la dinámica del sector chileno de XFNT. Según Gwynne (1998), la cadena de fruta global impulsada por el comprador se puede dividir en cuatro partes: el consumo; el marketing y la venta minorista; la distribución, incluyendo el transporte y el almacenamiento en frío; y la producción. Los lazos entre estas cuatro funciones no involucran usualmente una propiedad directa, sino que se basan en una 'red' de acuerdos contractuales. ${ }^{8}$ Estos acuerdos incluyen: el contrato informal entre los consumidores y su cadena de supermercado preferida; los contratos más formales que existen entre las cadenas de supermercados y los mayoristas e importadores, por una parte, y los diferentes tipos de compañías exportadoras de fruta (las transnacionales y los con-

\footnotetext{
${ }^{8}$ Aunque esto es cierto, en general las tendencias actuales indican una creciente inclinación hacia una integración vertical completa en la economía global de la fruta. Un buen ejemplo es la reciente adquisición de Fresh del Monte por el conglomerado árabe, quien posee United Trading Company y tiene el objetivo de aumentar la integración (Friedland et al., 1998).
}

sorcios de agricultores individuales), por otra parte; por último, también se incluyen los contratos entre las empresas exportadoras y los productores. En Gwynne (1998) se conceptualiza el bosquejo chileno desde una perspectiva de comercio minorista y marketing en el Reino Unido.

En el Reino Unido, los supermercados representan a los principales agentes del comercio minorista de la cadena recibiendo un $64 \%$ de la fruta chilena importada. Los mayoristas reciben un $34 \%$, el que se vende a los minoristas y a los supermercados. De acuerdo a Gwynne, los supermercados y los minoristas tienen contratos con cuatro diferentes tipos de agentes de distribución responsables del marketing de la fruta chilena. Ellos son: empresas frutícolas a mayor o mediana escala como Dole, Chiquita, United Trading Company, Unifrutti y Zeus; empresas exportadoras chilenas que incluyen David del Curto, Copefrut, Río Blanco y Frusan; grandes consorcios de agricultores quienes usualmente subcontratan servicios entre el agricultor y el sector del comercio minorista; un gran número de pequeñas y medianas compañías exportadoras quienes participan en el abastecimiento de los mercados especializados (mercados de nicho).

\section{A. La articulación del cambio global. Los lazos entre las compañias exportadoras $y$ los productores}

Los lazos que existen entre los distribuidores y los productores (alrededor de 8.000 en Chile trabajando en 10.000 propiedades) son de gran importancia en el marketing internacional de la fruta chilena. Es crucial el hecho de que, dados los bajos niveles de reglamentación en el sector, las compañías exportadoras son receptáculos a través de los cuales 
los cambios económicos a altas escalas de resolución repercuten y provocan un impacto en las localidades. La naturaleza del rol de estas empresas tiene tres caras: el marketing, la adopción, adaptación y transferencia de la tecnología y la provisión de financiamiento para los agricultores.

1. El marketing. Las compañias exportadoras son cruciales en el marketing de los productos frutícolas chilenos de dos maneras principales. En primer lugar, ellas proveen los servicios necesarios para la preparación, el embalaje y el almacenamiento en frío de la fruta. En segundo lugar, ellas reúnen cantidades suficientes de mercancía para justificar la inversión en tales servicios, obtener economías de escala del transporte y generar un poder negociador de precios en los países recibidores. Esto es de particular importancia para los pequeños productores, quienes tienen que enfrentar barreras considerables al comercializar sus productos independientemente.

2. La adopción, adaptación y transferencia de tecnología. El Plan de Desarrollo Frutícola de Frei en 1968 formó un piso importante para los avances tecnológicos en el mercado de la fruta (Jarvis, 1992). Sin embargo, en los años postgolpe, especialmente en los años setenta, el mismo sector quedó a cargo de sus propios recursos. Así, las empresas exportadoras jugaron un papel crítico en la identificación, adaptación y a la larga la transferencia de varias tecnologias frutícolas. Algunos ejemplos incluyen la adopción, adaptación y transferencia de la variedad Californian Thomson Seedless que la compañía chilena exportadora líder, David del Curto, llevó a cabo. También se incluye el desarrollo de técnicas de almacenamiento y de control de calidad del período crítico de la postcosecha de una gama de empresas (Jarvis, 1992).
3. La provisión de financiamiento para los agricultores. Tal vez el rol más importante de las empresas de marketing fue el de desarrollar un sistema de financiamiento para los agricultores. David del Curto fue fundamental en establecer este modelo de provisión de crédito en el cual las empresas efectivamente actuaron como bancos. Este sistema fue crucial en el desarrollo del sector de la pequeña agricultura ya que muchos bancos no estaban dispuestos a prestar dinero a los pequeños agricultores. En este sistema, el abastecimiento de la uva de exportación se asegura por medio de acuerdos contractuales (Korovkin, 1992). En el pasado estos acuerdos han incluido acuerdos de precio mínimo; sin embargo, la forma de contrato más frecuente sigue siendo el acuerdo a consignación a un año, como se explica más abajo.

$\mathrm{Al}$ agricultor se le ofrece el crédito a una tasa de interés real, en este momento alrededor de 8-12\%. Este anticipo se usa normalmente para cubrir todos los costos de producción más una proporción de los gastos de vida. Se espera que el agricultor siga un estricto programa de aplicación de insumos a lo largo de la temporada. En muchos casos estos insumos sólo pueden ser proveídos por la empresa, la que envía a un(a) agrónomo(a) para monitorear la operación. Una vez que se ha cosechado el producto, el agricultor lo envía al servicio de embalaje, en la fecha que la empresa lo exige. La fruta debe cumplir con los requisitos estipulados en el contrato, de lo contrario no será aceptada por la empresa. Una vez embalada, la fruta se traslada para ser refrigerada y luego transportada. El pago de la fruta se lleva a cabo a través del sistema de precios a consignación. Así, el retorno neto será equivalente al precio total recibido por la fruta menos el total del anticipo más el interés, junto con el costo de insumos y/o la maquinaria proveída por 
Warwick E. Murray

la firma (que algunas veces incluye la mano de obra) más un margen de ganancia para la empresa por estos ítemes, los cargos por los servicios del(a) agrónomo(a) y una comisión (entre 8-12\% de retorno bruto). Cuando un agricultor está endeudado, los costos pueden también incluir otra tasa de interés sobre el monto de la deuda (usualmente 10\%). Puede que la deuda se presente cuando el retorno bruto del agricultor no sea suficiente para cubrir los anticipos de crédito, los costos y el interés. Normalmente, una cláusula sobre deudas estipula que el agricultor deberá entregar toda su producción exclusivamente a la empresa hasta que haya cancelado todas las deudas.

En los años ochenta, virtualmente todas las compañias exportadoras ya involucradas y también entrando en el sector utilizaron el sistema de crédito de contrato y consignación (CCC). Así, en los años del boom, a mediados de los años ochenta, hubo una explosión en los niveles de crédito disponibles para los productores. En este período, muchos de los pequeños agricultores se incorporaron al sistema.

\section{B. El difícil periodo de principios de la década de los años 90 y la reestructuración del sector exportador}

Como se ha dicho anteriormente, en 1989, 1992 y 1993 el valor nominal del sector exportador frutícola se redujo. Esta situación se debió a tres factores: 1) El rápido aumento del valor del peso con relación al dólar durante este período; 2) $\mathrm{El}$ ingreso de nuevos competidores en los mercados globales de fruta en ese período (especialmente Sudáfrica); 3) Un creciente proteccionismo en las economías avanzadas, especialmente en los mercados de la manzana de la Unión
Europea donde la competencia con los productores locales es alta. Lo anterior condujo a una disminución significativa en el valor real de las ganancias por exportación de fruta (Murray, 1998a), las cuales en 1994 alcanzaron su punto más bajo en 8 años.

Esta tendencia dio origen a una significativa reestructuración de las operaciones de las compañías exportadoras, las cuales, a su vez, tuvieron un impacto devastador en muchos productores de fruta - especialmente los productores a menor escala. El mercado se ha reestructurado de tres formas principales:

- En primer lugar, las presiones del mercado han alentado la formación de las compañías exportadoras 'descomprometidas'. Estas empresas no participan en el complejo sistema ccc. Más bien, ellas actúan como simples intermediarios comprando y vendiendo los productos generalmente contratando los servicios y la infraestructura de las empresas más grandes para su actividad de postcosecha. De esta manera, tales compañías han reducido sus riesgos pudiendo explotar más fácilmente los mercados de nicho y retirarse fácilmente si es necesario. Debido al hecho de que las empresas 'descomprometidas' requieren productores independientes en términos de capacidad financiera y tecnológica, los pequeños productores generalmente no participan en este sistema.

- Un segundo cambio reciente, dada la evolución de las relaciones de contrato más estrictas con muchas empresas exportadoras, ha sido el aumento de asociaciones exportadoras de productores mayores. Según un productor mayor en el Norte Chico de Chile, la escala minima de eficiencia de este tipo de empresa es de alrededor de 100.000 cajas por año. Este requisito junto con la inver- 
sión pertinente han sido los dos factores que han impedido la formación de asociaciones de pequeños productores.

- En tercer lugar, algunas empresas participan en la compra de tierra y la organización de su propia producción. A menudo estos terrenos han pertenecido anteriormente a productores desplazados quienes han perdido su tierra durante un período de paralización económica.

Los cambios anteriores, sin embargo, están ocurriendo mayormente en la periferia del mercado. En la mayoría de los casos, el modelo organizacional CCC persiste. Además, un número de empresas que anteriormente ofrecian precios garantizados han virado hacia este sistema después de sufrir pérdidas severas debido a malos cálculos durante el empeoramiento de la economía en 1989 y 1992-93 (Gómez, 1996). No obstante, este sistema, y en particular la naturaleza de la negociación y acuerdos sobre los contratos, ha evolucionado considerablemente. El análisis de 40 contratos a consignación, 20 de 1986 y 20 de 1994, muestra un significativo aumento en la rigurosidad de las condiciones contractuales, la cual ha incluido pagos con altos intereses, comisiones y la introducción de varias cláusulas adicionales. Las empresas también han alentado la hipoteca de la propiedad y/o de los viñedos, incorporando esto a los acuerdos contractuales. Finalmente, las exigencias de calidad han aumentado entre los dos períodos. Tres cláusulas adicionales son dignas de mencionar:

- En la cláusula 'arbitraria' la empresa preselecciona un(a) abogado(a) quien arbitra en caso de existir una disputa entre las dos partes. En muchos casos la empresa predispone seriamente el resultado de los procedimientos lega- les al seleccionar el/la abogado(a) oficial de la compañía.

- En la cláusula en el 'área de la jurisdicción' la empresa indica en qué lugar físico se deben resolver las disputas. Las empresas que funcionan en las áreas periféricas del país a menudo seleccionarán Santiago, ya que así la posibilidad de que los reclamos se hagan públicos es mucho menor.

- En tercer lugar, como una reacción directa al episodio de las 'uvas envenenadas', los contratos de 1993 incluyeron una cláusula de 'catástrofe externa'. Así, debido a un bloqueo inesperado por guerra, secuestro o cualquier otro factor, a los productores se les devuelve su fruta, la que recogen donde ésta se encuentre en ese momento. De esta manera, la firma al liberarse de la responsabilidad en un momento de crisis, puede evitar cualquier petición de compensación.

La increíblemente exacta naturaleza de este tipo de acuerdo se ha ganado el nombre de 'el contrato león' en los círculos legales chilenos. El término se refiere a los contratos diseñados para funcionar casi exclusivamente en ventaja de la parte dominante. El impacto sobre muchos productores de este contrato ha acarreado un aumento en la dependencia de las empresas exportadoras y una obligación de aceptar un creciente despliegue de los riesgos que se corren en la operación de un sistema global. Los agricultores que operan bajo este sistema están a la vez insertos en un sistema global donde sus ganancias son determinadas por factores globales que están más allá de su control. 
Warwick E. Murray

VI. EL BOOM DE LA FRUTA Y EL
DESARROLLO DESIGUAL

A pesar del 'éxito' del sector exportador frutícola chileno a una escala macroeconómica, el aumento de XFNT en Chile está produciendo una gama de tensiones sociales, económicas y ambientales en el campo chileno. Tales tensiones, junto al desarrollo espacial desigual, la diferenciación social local y los impactos ambientales locales, son exploradas a continuación. Se argumenta que estas tensiones han evolucionado en gran parte debido a la incapacidad del Estado chileno para reglamentar el impacto de las fuerzas económicas globales. Esto se debe a una continua adherencia a una política económica y social neoliberal en el sector rural y en la economía en general. Irónicamente, se argumenta que si no se controlan tales tensiones éstas pueden explotar su potencial de socavar la capacidad del sector de sostenerse a largo plazo, la que ahora juega un papel central en el desarrollo económico.

\section{A. El desarrollo espacial desigual en el Chile rural}

La inequidad espacial se ha exacerbado debido a la influencia del boom de las XFNT (Cruz, 1987; Gómez y Echeñique, 1986; Gwynne y Ortiz, 1997). Muchas de las localidades rurales y en algunos casos regiones completas han sido marginadas del sistema dinámico. La ideología de un libre mercado, que ha continuado durante los gobiernos democráticos de Aylwin (1990-94) y Frei (199499), ha impedido el desarrollo de una política regional coherente diseñada para corregir un desequilibrio espacial.

1. La diferenciación interregional. En Chile los huertos de fruta se ubican entre la III Región en el Norte (Atacama) y la IX Región (La Araucanía). Sin embargo, en 1993, más de 155.000 hectáreas de un total de 178.000 con fruta se concentraban en las cinco regiones: entre la IV y la VII (incluyendo la Región Metropolitana) (Murray, 1997b). Sólo poco más de un $50 \%$ del total de la tierra usada para cultivos frutícolas se encontraba en la VI Región y la Región Metropolitana. Los aumentos en la producción, al igual que los crecientes ingresos per cápita, han sido algunos de los beneficios para las regiones especializadas en la exportación de fruta. Este ha sido el caso en especial de la regiones que no han estado involucradas en la producción de cosechas de exportación como la IV Región.

Por otra parte, debido a razones climáticas y de ubicación (cercanía a servicios portuarios, temporada de cosecha, nivel de infraestructura), en las regiones más 'periféricas', la agricultura tradicional (usualmente la de consumo local que incluye trigo, maíz, remolacha y productos lácteos) domina las economías rurales regionales. En este momento, dada la variedad de acuerdos de libre comercio que evolucionan en la región (Mercosur y NAFTA), junto con una continua reticencia por parte del Gobierno a 'interferir' en el mercado, parece casi imposible que la relativa posición del sector no exportador pueda mejorar (Kay, 1997).

2. La diferenciación intrarregional. Dentro de las regiones que cultivan fruta, la distribución de los beneficios también se ha concentrado espacialmente. Ciertas localidades -donde existen ventajas comparativas y competitivas en la producción de cultivos para la exportaciónhan disfrutado una abrumadora cantidad de beneficios (Riffo-Rosas, 1992). Por ejemplo, en la IV Región ha habido una considerable diferenciación espacial entre comunas. En Monte Patria, las exportaciones han prosperado con mucha fuerza. Aquí convergen considerables 
variables climáticas que permiten la cosecha en el momento perfecto para el mercado de Navidad en Norteamérica. La existencia de un abastecimiento de agua permanente (notablemente regulada por los embalses La Paloma y Cogotí) ha apoyado el crecimiento local (Gwynne y Meneses et al., 1994). En la comuna ubicada al Sur de Monte Patria, Punitaqui, la temporada de cosecha es demasiado tarde para beneficiarse de los altos precios contraestacionales en Estados Unidos. Además se tiene que mejorar la infraestructura de abastecimiento de agua de una manera coherente. En consecuencia, una de las comunas de crecimiento más rápido es vecina con una de las comunas más pobres en Chile. Aun dentro de las comunas, debido a una mezcla intrincada de características de infraestructura, de ubicación, de historia y de clima, el impacto espacial del crecimiento de las XFNT ha sido desigual. En Monte Patria, por ejemplo, Valle Limarí Alto tiene un microclima particularmente favorable, recibiendo agua de manera permanente en una tierra fértil y plana, la que tiene una historia de reforma agraria. Por lo tanto, se ha visto un enorme crecimiento en la exportación de uva de mesa (centrada en el pequeño pueblo rural llamado El Palqui). Cerca, en el valle Río Grande, sin embargo, ha habido muchos problemas que han impedido el desarrollo de la agricultura para la exportación. Por ejemplo, hay problemas de abastecimiento de agua, aislamiento y una vulnerabilidad a la sequía, lo que conforma una importante explicación para la alta incidencia de pobreza rural en el valle (Ortiz y Schiappacasse, 1993).

También existe evidencia que sugiere que el boom de las XFNT favorece una inclinación urbana (Gwynne y Ortiz, 1997). Por ejemplo, algunos centros urbanos regionales, tales como Ovalle (IV Región) y Curicó (VII Región) han cauti- vado considerables beneficios multiplicativos a través del desarrollo del sector de servicios, por ejemplo financieros, de información y asistencia, de alojamiento, de entretención y transporte $\mathrm{y}$, en algunos casos, sectores manufactureros como insumos y maquinaria (Murray, 1997a). Por otra parte, la baja calidad de los niveles de abastecimiento y otras actividades siguen caracterizando las áreas de producción y sus pequeños pueblos y asentamientos.

\section{B. El crecimiento de las XFNT y la diferenciación socio- económica en el Chile rural}

Dentro de las localidades que participan en el sistema, las diferencias entre los grupos socioeconómicos se han agudizado. Por ejemplo, los que no poseen tierras, los/las trabajadores(as) temporeros(as) y los pequeños agricultores (especialmente los minifundistas) están en una relativa desventaja dentro de la sociedad rural (Kay, 1997; Murray, 1997b). La siguiente sección se centra en la diferenciación en los mercados laborales al igual que entre los grupos con tierras de diferente superficie.

1. Los mercados laborales diferenciados. En todas la regiones y localidades que se especializan en XFNT, el empleo rural ha aumentado debido a una creciente demanda por trabajo agrícola y de embalaje. Una diferencia en el mercado laboral, que a menudo es considerada positiva, es el alcance que se le ha dado a la mano de obra femenina en el embalaje de la fruta. En muchos casos, esto ha llevado a las mujeres a emplearse fuera de la casa por primera vez, lo que les ha conferido cierto nivel de independencia económica, y que según algunos comentaristas es un paso importante para compensar la dañina y tradicional estructura social patriarcal que existe en el Chile rural (Bee y Vogel, 1997). 
No obstante, la recompensa por el trabajo en el mercado laboral frutícola es diferenciada de acuerdo al estatus del trabajo (temporario y no temporario) y al género. En el caso del primero, una proporción significativa de la creciente demanda laboral es de naturaleza temporaria (Riffo-Rosas, 1995). Esto ha originado una inseguridad económica para la mano de obra durante la no temporada, al igual que una gama de problemas asociados con la afluencia migratoria en busca de trabajo para la temporada (Ortiz, 1990). Además, dentro de este sector los salarios permanecen más bajos que en el sector laboral permanente. Este es el caso en particular de la mano de obra femenina para el embalaje, que generalmente recibe menos que la masculina por un día de trabajo. Varias de las temporeras rurales también se han quejado del trauma de trabajar "jornada doble' ya que ellas trabajan cada vez más fuera de la casa en las horas del día con luz natural (Barrientos, 1997). A la fecha, ha habido muy pocos avances en el aspecto de sindicalización y opción que el golpe de Estado eliminó y que el gobierno democrático todavía no ha resuelto (Barrientos, 1997; Kay, 1997).

2. La marginalización y la proletarización de los pequeños agricultores. $\mathrm{El}$ aumento de las XFNT en Chile ha tenido un impacto diferente en los diversos grupos de agricultores. Como ya se ha mencionado, la posición relativa de muchos agricultores tradicionales, sin acceso al mercado de XFNT, ha empeorado. Este ha sido especialmente el caso de los minifundistas, quienes han estado severamente limitados para obtener el crédito necesario para iniciar la producción de fruta (Kay, 1997). El iniciar un cultivo es un proceso costoso. Por ejemplo, en el Norte Chico, el cultivar sólo una hectárea de uva de mesa puede costar hasta US\$35.000. En el Valle Central, donde el abastecimiento de agua es abundante, el costo es considerablemente menor, pero aún prohibitivo para los pequeños agricultores. Desde la restauración de la democracia en Chile, el debate se ha centrado principalmente en la reconversión como una estrategia de sobrevivencia para los pequeños agricultores. Así a éstos se les motiva a convertir su producción en cultivos que sean competitivos en el mercado global tales como la fruta. Existe un creciente consenso de que los pequeños agricultores, en particular, enfrentan una serie de restricciones que pueden dificultar los esfuerzos de 'reconvertir' seriamente. Estas incluyen la falta de financiamiento, de información, de poder de negociación y la necesidad de asegurar el ingreso para la subsistencia como también de minimizar los riesgos. Dado este consenso, dentro del contexto de la política postdictatorial de "neoliberalismo con un rostro humano', el gobierno le ha puesto más atención a los agricultores "viables' poniendo a su disposición fondos limitados para 'reconvertir' (Kay, 1997).

No obstante, estudios recientes han demostrado que la sola reconversión a la producción de fruta no es suficiente para garantizar la sobrevivencia de los pequeños agricultores. En el sector capitalista agrofrutícola parece haber una diferenciación en desarrollo en términos del tamaño de la parcela o fundo. Los grandes agricultores (con 50 hectáreas y más) se han beneficiado claramente con el desarrollo de la exportación frutícola. Sin embargo, los pequeños y medianos agricultores enfrentan grandes dificultades dentro del contexto neoliberal. En general, tales agricultores fueron incorporados a través de contratos con empresas exportadoras de fruta, a menudo multinacionales, como se ha dicho anteriormente. Estos contratos han sido elaborados explotando asimetrías en el poder económico y político existente entre las firmas y los agricultores. Esta asi- 
La globalización de la fruta, los cambios locales y el desigual desarrollo rural en América Latina

metría ha creado una situación donde las firmas han podido establecer un sistema de contrato que funciona claramente a su favor. Dado el bajo poder de negociación, los pequeños agricultores tienen pocas alternativas a aceptar las condiciones de estos documentos contractuales. Esto ha permitido a las empresas alterar el sistema transfiriendo una proporción importante de los costos de operación y proteger sus márgenes de rentabilidad en tiempos difíciles. Tales problemas se han agravado aún más por el hecho de que a muchos de los pequeños agricultores se les ha alentado (y algunas veces obligado) a practicar monocultivos en sus tierras para poder obtener economías de escala. Lo anterior ha aumentado la vulnerabilidad económica $\mathrm{y}$ ambiental junto con presenciar el desplazamiento de la producción sostenible originando una inflación en los costos de consumo de alimentos $(\mathrm{Mu}-$ rray, 1998b).

Una gran proporción de los parceleros del sector frutícola está sumamente endeudada con las compañías. Cada vez más los agricultores están teniendo que entregar sus tierras en pago de estas deudas. Los productores que han tenido la desgracia de quedarse sin tierra generalmente tienen que recurrir a empleos de temporada mal pagados o a actividades informales; algunos de ellos están migrando a las ciudades. Como consecuencia, en el sector productor frutícola chileno se puede ver claramente la reconcentración de la tierra (un aumento en el tamaño promedio de las tierras) ya que las empresas y los mayores productores obtienen cada vez más acceso a la tierra que ha pertenecido a los parceleros. En la tabla 1, las cifras de los niveles de endeudamiento de 26 agricultores encuestados en $1995^{9}$ en las dife-

${ }^{9}$ Las entrevistas a los pequeños productores formaron parte del trabajo en terreno para

\begin{tabular}{|lcc|}
\hline \multicolumn{3}{|c|}{ Tabla 1 } \\
$\begin{array}{r}\text { EndEUDAMIENTO PROMEDIO EN LAS PARCELACIONES } \\
\text { DE El PALGUI, 1995, IV REGIÓn }\end{array}$ \\
\hline Parcelación & $\begin{array}{c}\text { Deuda } \\
\text { promedio (US\$) }\end{array}$ & $\begin{array}{c}\text { Año promedio } \\
\text { de comienzo }\end{array}$ \\
\hline San Antonio & 84383 & 1987 \\
Los Litres & 49600 & 1991 \\
Santa Rosa & 31528 & 1988 \\
Total & 50217 & 1989 \\
\hline Fuente: Entrevistas personales en terreno.
\end{tabular}

rentes parcelaciones en la localidad rural de El Palqui (En el Valle Limarí, Norte Chico) reflejan el grado del problema.

La tabla 2 muestra el impacto del endeudamiento, en términos de la reconcentración en las tierras de la misma localidad. Similares encuestas realizadas a los pequeños productores de manzanas en el sector del Valle Central de Chile han revelado que procesos parecidos - aunque menos considerables- están teniendo lugar allí (Murray, 1998c). En estas áreas estudiadas, la tierra ha sido absorbida por mayores productores y

\begin{tabular}{|c|c|c|}
\hline \multicolumn{3}{|c|}{$\begin{array}{c}\text { Tabla } 2 \\
\text { DistriBución DEL TAMAÑo DE PROPIEDADES } \\
\text { EN EL PALQUI, } 1983 \text { Y } 1985\end{array}$} \\
\hline Tamaño & 1983 & 1994 \\
\hline$<10$ ha & $17 \%$ & $10 \%$ \\
\hline $10-20$ ha & $5 \%$ & $8 \%$ \\
\hline$>20<50$ ha & $4 \%$ & $9 \%$ \\
\hline$>50$ ha & $74 \%$ & $73 \%$ \\
\hline $\begin{array}{l}\text { Fuente: Cal } \\
\text { Internos. }\end{array}$ & los ro & estos \\
\hline
\end{tabular}

la investigación de una tesis doctoral en este tema. Este trabajo fue realizado en un periodo de un año en las localidades de Ovalle y Curicó en 1994 y 1995 (Murray, 1997b). 
Warwick E. Murray

compañías exportadoras en pago de sus deudas.

Por otra parte, los grandes agricultores han sobrevivido y, en algunos casos, prosperado dentro del ambiente especialmente competitivo de principios de la década de los noventa. Estos agricultores a mayor escala son de dos tipos: los que mantuvieron sus grandes terrenos después de las reformas agrarias de los años setenta permaneciendo en la agricultura y agricultores que administran sus tierras desde las áreas urbanas. Especialmente los productores con más de 200 hectáreas de terreno se han beneficiado frente a los menores agricultores en al menos cuatro aspectos: un relativo alto poder de negociación con las compañias exportadoras, lo que se tradujo en contratos en términos más favorables para ellos; un acceso a crédito y capital en fuentes diferentes de las compañías exportadoras, lo que significó menor dependencia y mayor flexibilidad; un mayor acceso y control de la información, lo que dio la posibilidad de planear las acciones a largo plazo incluyendo las inversiones productivas; y un mayor espectro para la diversificación a diferentes tipos de productos (incluyendo la producción de otros productos además de fruta) en terrenos relativamente amplios (Gwynne, 1998; Murray, 1999).

Como se puede apreciar, en el sector de los pequeños agricultores la marginalización, la carencia de tierra y una final proletarización son cada vez realidades más comunes en un sector que se supone relativamente dinámico en los círculos de Gobierno. La sola 'reconversión' no es una panacea y las altas ganancias del principio, gracias a la entrada en los mercados globales, duraron un corto plazo. Es interesante destacar que muchos de los pequeños productores que no quisieron o no pudieron orientar su producción a la exportación han permanecido en el sector, admitiendo recibir bajas ganancias a corto plazo, pero sobreviviendo basados en la producción para los mercados locales y en la subsistencia y la participación en los mercados laborales locales de la temporada en el sector frutícola.

\section{Las tensiones locales medio- ambientales}

La última característica del cambio local en ser investigada es aquella que se refiere a las tensiones locales ambientales. La rápida expansión de la intensiva agricultura frutícola está causando presiones en el medio ambiente local y regional especialmente los 'ambientes marginales' en el Norte (sobre todo en el Norte Chico) donde aumentan la escasez y la contaminación de agua además de la salinidad del suelo junto a otras formas de degradación del mismo (Gwynne y Meneses et al., 1994). En un estudio del sistema del Valle Limarí, Gwynne y Meneses et al. (1994) identificaron una gama de tensiones ambientales creadas a través de la rápida adopción y expansión de tierra con uva de mesa. En particular, los autores destacan que los rápidos patrones de adopción han generado severos problemas de abastecimiento de agua. Aunque el área se sirve de un número de embalses, la demanda por agua sobrepasa la cantidad abastecida. Lo anterior ha originado la utilización de métodos de irrigación cada vez más eficientes y costosos - principalmente el riego 'a goteo'- A pesar de que este tipo de riego ha compensado los problemas de escasez de agua inminentes, lo mismo ha tenido el impacto 'paradójico' de reducir el excedente de agua disponible para filtrar los suelos (Gwynne y Meneses et al., 1994). En consecuencia, la salinidad del suelo se ha transformado en un problema considerable en el área. Los problemas en esta región se han agravado debido al cambio climático lo- 
cal, el que ha originado una disminución constante en el promedio de agua caída al igual que un número de períodos de sequía en los últimos diez años (Downing, 1994).

Las tensiones ambientales no se han limitado a los sectores marginales solamente. En la 'reconversión' hacia la producción de fruta para la exportación, muchos agricultores han transformado su producción de un tipo relativamente diversificada/no-intensiva a una de monocultivo/intensiva. Este es el caso particular de los pequeños agricultores, quienes tienen poca opción de especializarse de esta manera, lo que está originando una degradación del suelo en muchas áreas. Además, el intensivo uso de pesticidas y herbicidas ha contaminado las aguas. Por el momento, no ha habido estudios a gran escala que investiguen estos procesos en detalle. Sin embargo, hay evidencia anecdótica acumulada en 1995 que parece apoyar éstos argumentos.

En el caso de la degradación de los suelos y la escasez de recursos, el más perjudicado es el agricultor más pequeño y más pobre. En el Norte Chico, por ejemplo, algunos pequeños agricultores están teniendo que dejar el mercado debido al rápido aumento de los precios del agua y de la necesidad de utilizar equipos de irrigación más sofisticados. Es más, dada la insistencia de las compañías exportadoras para que los pequeños agricultores practiquen el monocultivo en sus pequeñas parcelas, los problemas de la calidad del suelo se concentran justamente en estos terrenos. Así, las tensiones ambientales originadas por la rápida expansión de las XFNT chilenas exacerban la desigualdad social en el campo.

\section{El desarrollo rural desigual y el problema de la sustentabilidad en general}

El boom de la exportación de fruta chilena no ha traído beneficios ubicuos. Al contrario, el crecimiento de las XFNT ha precipitado y exacerbado desigualdad espacial y socioeconómica. Por otra parte, la operación del sistema ha desencadenado un número de tensiones que amenazan la sustentabilidad de los sistemas locales basados en la producción de fruta de la siguiente manera:

- En primer lugar y más obviamente, los problemas ambientales llevan a debilitar a los sectores locales. Este es el caso particular de las áreas marginales y en alguna medida también es cierto en general. Dado lo impredecible que es el sistema climático local reciente en el contexto de la oscilación de la Corriente del Niño, la posibilidad de sequías serias y debilitantes siempre está presente.

- En segundo lugar, en las localidades donde ha evolucionado una especialización de monocultivos casi por completo la vulnerabilidad a las fuerzas de cambio global es potencialmente peligrosa. Los gustos de los consumidores en los mercados recibidores están cambiando rápida y permanentemente al igual que las medidas proteccionistas, en particular en los sectores de economías avanzadas. Los pequeños agricultores, en especial, no tienen ni la habilidad ni la información para mantenerse al día con tales tendencias. Las empresas exportadoras, por otra parte, dada su creciente naturaleza descomprometida, bien pueden trasladarse a nuevas áreas donde existan cultivos de fruta que esté 'de moda'.

- En tercer lugar, algunos comentaristas arguyen que la continua exclusión de la mayoría de la población rural para 
Warwick E. Murray

recibir los beneficios del crecimiento de la exportación amenaza la sustentabilidad política del sistema (Vergara, 1994; Kay, 1995). La sociedad rural popular tal vez está perdiendo paciencia con el modelo de orientación exportadora. En el contexto de la restauración de la democracia en Chile (desde 1990) cada uno de estos agricultores tiene derecho a voto (lo use o no ). Ya el gobierno de la Concertación de Partidos Políticos está perdiendo votos debido a su percibida incapacidad de brindar un progreso social en el país en su totalidad.

Pareciera justificable argumentar que varias localidades especificas estaban mejor económicamente antes del 'empujón' hacia los mercados globales. En los sistemas tradicionales, la producción era destinada a las realidades y limitaciones locales y, a la larga, era más sostenible. Es desde esta perspectiva que los críticos del paradigma dominante de desarrollo podrían abogar por una propuesta 'alternativa'. Por otra parte, aún desde una perspectiva ortodoxa, la amenaza al sostenimiento local mencionado anteriormente pone en duda la adherencia al neoliberalismo, al menos en su forma actual.

\section{E. El legado del neoliberalismo en Chile}

Aunque el Estado chileno en sí, a través de su orientación hacia el exterior en el sector frutícola, no ha 'creado' los problemas mencionados - ya que éstos son sintomáticos de una exposición local a poderosas fuerzas globales de poder-, de todas maneras se le puede criticar por su continua reticencia a regular tales impactos. La adhesión a las políticas neoliberales de los gobiernos democráticos de Aylwin (1990-1994) y Frei (19941999) representa una continuidad de políticas más radicales que comenzaron bajo el régimen autoritario. Ha habido ciertas alteraciones marginales ya que los gobiernos democráticos han buscado aliviar algunas de las desigualdades mayores (Kay, 1997). No obstante, a pesar de los cambios en las políticas de gobierno hacia un 'neoliberalismo con un rostro humano' o a un 'cambio productivo con igualdad social' (Hojman, 1995), las políticas permanecen afianzadas dentro de un paradigma de libre mercado. La necesidad de un cambio fundamental en el sector rural chileno es cada vez más obvia. Sin embargo, existen prejuicios en contra de mayores esfuerzos para engendrar un sostenimiento, promover la igualdad y otorgar poder a los grupos rurales marginados. Estos prejuicios vienen de una presión internacional para no alterar radicalmente el enfoque como también son un 'vestigio' autoritario que incluye, entre otras cosas, la presencia de los senadores designados, quienes obviamente continúan impidiendo la aprobación de proyectos de leyes más 'progresistas'.

En el contexto de los temas de desarrollo rural desigual explorados en este artículo se puede responsabilizar claramente a la abrumadora ausencia de políticas globales y regionales, a la carencia de apoyo para los pequeños agricultores, al fracaso en asistir a los mismos en promover grupos sociales como cooperativas de productores $\mathrm{y}$, finalmente, a una pobre supervisión ambiental y regulatoria. Podría decirse, sin embargo, que bajo todos estos fracasos en la reglamentación yace la completa incapacidad y falta de voluntad del Estado para enfrentar al sector de las empresas exportadoras y diseñar métodos de incentivos para que así éstas no actúen de una manera miope y corta de miras. En la ausencia de tales medidas, las políticas de las empresas exportadoras están siendo decisivas en las localidades creando gran dependencia determi- 
nada en gran parte por los intereses creados de las mismas.

Las alternativas al paradigma actual siguen evolucionando. Se debe destacar a los/las pensadores/as de CEPAL quienes están comprometidos en la elaboración del 'neoestructuralismo'. Algunas de las ideas de esta escuela ya están penetrando los círculos de Gobierno. No obstante, los críticos de este enfoque en evolución arguyen que éste es sólo un intento de 'juguetear con los márgenes'. Dada la arraigada naturaleza de la política chilena y de la presión internacional, es posible que pase mucho tiempo antes de que se reconozca un paradigma verdaderamente nuevo y que realmente se ponga en práctica.

\section{LAS REPERCUSIONES DE LA GLOBALIZACIÓN DE LA FRUTA PARA AMÉRICA LATINA}

La globalización de la agricultura y, en particular, de la fruta, se está ampliando y profundizando, formando y conectando un despliegue de macroeconomías, regiones y localidades. Los beneficios de tales cambios, al menos a una macroescala, pueden ser muy significativos. Sin embargo, la globalización es desigual y contradictoria. A través de la creación de una red interconectada, esta globalización margina a aquellos lugares y grupos que no participan en el proceso. Entre aquellas entidades que sí participan, la distribución de los beneficios no es equitativa debido a las asimetrías subyacentes en el poder global. En Chile, la discusión anterior ha mostrado que estas posibilidades se manifiestan espacial, social y ambientalmente. Se han dejado al descubierto similares impactos en otros países de América Latina involucrados en el complejo. Por ejemplo, en El Salvador y Paraguay se han observado similares procesos de degra- dación ambiental, carencia de sustentabilidad económica y diferenciación social (Barham et al., 1992; Carter et al., 1996). En particular, Carter et al. (1996) destacan que el crecimiento 'exclusionario' (la carencia de tierra entre pequeños productores con una tasa de empleo rural en disminución) ha aumentado como consecuencia de un desarrollo orientado hacia el exterior en Paraguay. En general, parece factible argumentar que efectivamente existe una tendencia al crecimiento exclusionario y no sustentable en la economía rural de exportación en América Latina (Murray, 1998a; Kay, 1995). Tal tendencia no se limita a América Latina; investigaciones preliminares en los países del Pacífico Sur han revelado procesos similares. Por ejemplo, en Tonga, la campaña por aumentar las exportaciones de fruta y calabaza está creando tensiones ambientales, políticas y económicas en el campo (Overton, Murray y Ali, 1999). Es posible que tales procesos se extiendan a otros países también.

Los modelos de la globalización de la agricultura y el enfoque de la cadena de la mercancía no presuponen (ni tampoco deberían hacerlo) un rol determinante en las fuerzas de la economía global, en la incapacidad de los actores locales de reconstituir el sistema global o en la evolución de la dependencia a un nivel local. En estos términos, el rol del Estado regulador o de la sociedad civil (o tal vez ambos) puede, en teoría, reducir y quizás 'optimizar' el impacto del cambio global. Lo anterior no sorprende dado que se han desarrollado diversas ideas en y para los países capitalistas avanzados donde tales condiciones se han establecido firmemente (aunque estén en decadencia). En la realidad contemporánea de Chile y América Latina, sin embargo, el sistema opera de manera diferente. En última instancia, el consenso neoliberal, que está impregnando 
Warwick E. Murray

la región debido a una combinación de intereses de una elite local e internacional, impide el establecimiento de un enfoque alternativo. Con el objetivo de atenuar las fuerzas del proceso de globalización de la agricultura en América Latina es tiempo de explorar y poner en práctica un nuevo paradigma de desarrollo rural.

\section{REFERENCIAS}

Apey, A. (1995) Agricultural restructuring and Co-ordinated Policies for Rural Development in Chile, tesis doctoral, University of Birmingham (UK).

Asociación de Exportadores (varios años) Estadísticas de Exportaciones Hortofrutícolas, $\mathrm{AE}$, Santiago.

Barham, B., Clark, M., Katz, E. y Schurman, R. (1992) "Nontraditional Agricultural Exports in Latin America", Latin American Research Review, vol. 27, p. 43-82.

Barrrientos, S. (1997) "The Hidden Ingredient: Female Labour in Chilean Fruit Exports”, Bulletin of Latin American Research, vol. 16, no. 1, p. 71-81.

Bee, A. y Vogel, I. (1997) "Temporeras and Household Relations: Seasonal Employment in Chile's Agroexport Sector", Bulletin of Latin American Research, vol. 16, p. 83-95.

Bosworth, B., Dornbusch, R. y Laban, R. (1994) The Chilean Economy: Policy Lessons and Challenges, The Brookings Institute, Washington.

Carter, D. y Turner, D. (1988) Cool Chain Developments, Institute of Grocery Distribution/National Farmers Union, Watford (UK).

Carter, M. R., Barham, B. y Mesbah, D. (1996) "Agricultural Export Booms and the Rural Poor in Chile, Guatemala, and Paraguay", Latin American Research Review, vol. 31, p. 33-65.

Chilean-American Chamber of Commerce (1990) "Editorial", Journal of the
Chilean-American Chamber of Commerce, October edition.

Cloke, P., Philo, C. y Sadler, D. (1991) Approaching Human Geography, Chapman, London.

Cook, R. (1990) "Challenges and Opportunities in the US Fresh Produce Industry", Journal of Food Distribution Research, February, p. 67-74.

Cruz, M. E. (1987) "Pobladores y Cambio Agrario en el Sector Agrícola en Chile", Estudios Rurales Latinoamericanos, vol. 10, p. 341-353.

Dietz, J. L. (1995) "Overcoming Underdevelopment: What has been learned from the East Asian and Latin American Experiences", en J. L. Dietz (ed.), Latin America's Economic Development: Confronting Crisis, Lynne Rienner, London.

Downing, T. E. (1994) "Climate Change and Sustainable Development in the Norte Chico, Chile: Climate, Water resources and Agriculture", Occasional Publication 35, School of Geography, University of Birmingham.

Friedland, W. H. (1994) "The Global Fresh Fruit and Vegetable System: An Industrial Organisation Analysis", en Philip McMichael (ed.) The Global Restructuring of Agro-Food Systems, Cornell University Press, Ithaca.

Friedland, W. H., Barton, A. E y Thomas, R. (1981) Manufacturing Green Gold: Capital, Labor and Technology in the Lettuce Industry, Cambridge University Press, New York.

Friedland, W. H., Morvaridi, B., Murray, W. E, Renard, M., y Vogel, I. (1998) "The Fresh Del Monte Story- Shenanigans in the Global Fruit Sector", Quadrennial World Congress of Sociology, Montreal, Quebec, 26 junio-1 agosto.

Friedmann, H. y McMichael, P. (1989) "Agriculture and the State System: The Rise and Decline of National Agricultures: 1870 to the present", Sociologia Ruralis, vol. 29, p. 138-170. 
La globalización de la fruta, los cambios locales y el desigual desarrollo rural en América Latina

Gereffi, G. (1994) "Capitalism, Development and Global Commodity Chains", en Sklair, L. (ed.) Capitalism and Development, Routledge, London, p. 21131

Giddens, A. (1984) The Constitution of Society, Polity Press, Cambridge.

Gómez, S. (1996) Exportación de frutas Chilenas. El caso de la manzana, FLACso, Santiago, Chile.

Gómez, S. y Echeñique, J. (1986) Nuevos Empresarios y Empresas Agrícolas en Chile, Documento de Trabajo 277, FLACSO, Santiago.

Gwynne, R. N. (1990) New Horizons? Third World Industrialisation in an International Framework, Longman, London.

Gwynne, R. N. (1998) "Globalization, Commodity Chains and Agriculture in Latin America”, ISS Rural Seminar Series, The Hague, Netherlands, Feb. 16

Gwynne, R.N. y Kay, C. (1997) "Agrarian Change and the Democratic Transition in Chile: an Introduction" Bulletin of Latin American Research, vol. 16, no. 1, pp. 3-10.

Gwynne, R.N. y Meneses, C., Ortiz, J., Downing, T. E., Santibañez, F., Romero, H. y Bradshaw, M. (1994) Climate Change and Sustainable Development in the Norte Chico, Chile: Land, Water and the Commercialisation of Agriculture, Occasional Publication No. 34, University of Birmingham.

Gwynne, R. N. y Ortiz, J. (1997) "Export Growth and Development in Poor Rural Regions: a Meso-Scale Analysis of the Upper Limari”. Bulletin of Latin American Research, vol. 16, no. 1, p. 25-41.

Hojman, D. E. (ed.) (1993) Change in the Chilean Countryside: From Pinochet to Aylwin and beyond, Macmillan Press. London.

Hojman, D. E. (ed.) (1995) Neo-liberalism with a Human Face? The Politics and Economics of the Chilean Model, Institute of Latin American Studies,
University of Liverpool, Monograph Series no. 20.

Jarvis, L. S (1992) "Changing Private and Public Sector Roles in Technological Development: Lessons from the Chilean Fruit Sector", Department of Agricultural Economics, University of California.

Johnston, R. J. (1991) Geography and Geographers, Edward Arnold, London.

Kay, C. (1974) "Agrarian Reform and the Transition to Socialism in Chile", Journal of Peasant Studies, vol. 2, p. 418-445.

Kay, C. (1995) "Rural Development and Agrarian Issues in Contemporary Latin America" en Weeks, J. (ed.) Structural Adjustment and the Agricultural Sector in Latin America and the Caribbean, Macmillan Press, London.

Kay, C. (1997) "Globalisation, Peasant Agriculture and Reconversion", Bulletin of Latin American Research, vol. 16, no. 1, p. 11-24.

Korovkin, T. (1992) "Peasants, Grapes and Corporations: The Growth of Contract Farming in a Chilean Community", Journal of Peasant Studies, vol. 19, no. 2.

Le Heron, R. (1993) Globalised Agriculture, Pergamon Press, Oxford.

Llambí, L. (1991) "Latin American Peasantries and Regimes of Accumulation", European Review of Latin American and Caribbean Studies, No.51.

Murray, W. E. (1997a) "Competitive Global Fruit Export Markets: Marketing Intermediaries and Impacts on SmallScale Growers in Chile", Bulletin of Latin American Research, vol. 16, no. 1, p. 43-55.

Murray, W. E. (1997b) Neoliberalism, Restructuring and Nontraditional Fruit Exports in Chile: Implications of Outward-Orientation for Small-Scale Growers, tesis doctoral, University of Birmingham, UK.

Murray, W. E. (1998a) "The Globalisation of Fruit, Neoliberalism and the Ques- 
Warwick E. Murray

tion of Sustainability. Lessons from Chile", European Journal of Development Studies, 10(1), p. 201-227.

Murray, W. E. (1998b) "The Global Agrofood Complex, Neoliberalism and Small Farmers in Chile: Lessons for the Pacific Islands?", Journal of Pacific Studies, vol. 22, p. 27-60.

Murray, W. E. (1998c) 'Don't tip the Apple Cart-Global Apples, Neoliberalism and Small Scale Growers in Chile, USP Geography Working Paper Series, no. $1,63 \mathrm{pp}$.

Murray, W. E. (1999) "Natural Resources, the Global Economy and Sustainability” en Gwynne R. N. y Kay C. (eds.) Latin America Transformed: Globalisation and Modernity, Edward Arnold, London, p. 128-151.

Ortiz, J. (1990) "Impacto Sociogeográfico de la Modernización Agrícola en Dos Valles del Semi-árido Chileno", Revista Geográfica de Chile Terra Australis, 33: 61-78.

Ortiz, J. y Schiappacasse P. (1993) “Percepción Espacial de Grupos Sociales Vulnerables Frente a Eventos Climáticos: Valle de Limarí" Project Report for FONDECYT, No. 92-1112.

Overton, J., Murray, W. E. y Ali, I. (1999) "Commodity production an unsustainable agriculture" en Overton, J. y Scheyvens, R. (eds.) Strategies for Sustainable Development: Experiences from the Pacific. Zed Books, London. p. 168-181.

Riffo-Rosas, M. (1992) "Modernización Agrícola y Expansión de la Frontera en el Semi-árido Chileno", paper pre- sented at XI National Congress of Geography, Talca, Chile, October.

Riffo-Rosas, M. (1995) "Identidad Social y Pertenencia Territorial de los Temporeros Frutícolas de la Zona Central, VI y VII Regiones", Anales de la Sociedad Chilena de Ciencias Geográficas, May.

Shepherd, A. (1998) Sustainable Rural Development, Longman, London.

Sunkel, O. (ed.) (1993) Development from Within: Towards a Neo-structuralist Approach for Latin America, Lynne Rienner, Boulder and London.

Universidad Católica (1991) Impact of Policy Reforms on the Agricultural Sector in Chile, Informe de Coyuntura no. 25, Departamento Economía Agraria, Universidad Católica, Santiago.

Universidad Católica (1993) Oportunidades y Desafios Competitivos de la Fruticultura de Exportación de Chile, Serie de Investigación no. 65, Departamento Economía Agraria, Universidad Católica, Santiago.

Vergara, P. (1994) "Market Economy, Social Welfare and Democratic Consolidation in Chile", en Smith, W., Acuña, C. y Gamarra, E. Democracy, Markets and Structural Reform in Latin America: Argentina, Bolivia, Brazil and Chile and Mexico, North-South Center, University of Miami.

Whatmore, S. (1995) "From Farming to Agribusiness: the Global Agro-food System", en Johnson R. J., Taylor, P. J. y Watts, M. (eds.) (1995) Geographies of Global Change, Blackwell, London. 
La globalización de la fruta, los cambios locales y el desigual desarrollo rural en América Latina 